\title{
ESTADO, POLÍTICAS E AGENCIAMENTOS SOCIAIS EM SAÚDE
}

STATE, POLICIES AND SOCIAL ASSEMBLAGES IN HEALTH

ESTADO, POLÍTICAS Y AGENCIAMIENTOS SOCIALES EN SALUD

Priscila Farfan Barroso (ID $ه$

Programa de Pós-Graduação em Antropologia Social da Universidade

Federal do Rio Grande do Sul I Porto Alegre - RS - Brasil 
Sônia Weidner Maluf Érica Quinaglia Silva organizaçắ

\section{ESTADO, POLÍTICAS} E AGENCIAMENTOS SOCIAIS EM SAÚDE

Etnografias comparadas

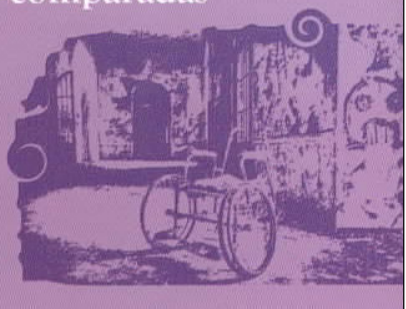

Q editora ufsc

Maluf, S. W., e Quinaglia Silva, E. (Org.). 2018.

Estado, políticas e agenciamentos sociais em saúde. Florianópolis: Editora da UFSC.

A obra "Estado, políticas e agenciamentos sociais em saúde”, organizada por Sônia Maluf e Érica Quinaglia Silva, é indispensável para estudiosos da área de Saúde Pública e para profissionais das Ciências Humanas que estabelecem estudos transversais com esses campos de conhecimento.

Composta por etnografias, realizadas em profundidade, a coletânea está dividida em duas partes, com focos diferentes, mas complementares, para a análise da complexidade em saúde pública. A primeira delas retrata aspectos institucionais, estatais e concernentes às políticas públicas a partir da perspectiva das práticas de Estado, e a segunda apresenta os agenciamentos e as experiências vividas por quem demanda e se mobiliza por serviços de saúde.

Dos 12 capítulos, seis são dedicados à reflexão na área de saúde mental, tendo como mote a loucura, a adicção e as políticas públicas, e os outros artigos perpassam as temáticas do aborto legal, da gestão de pacientes, da hanseníase, do envelhecimento, dos cuidados tradicionais e das doenças raras. Cabe destacar, ainda, que a grande maioria dos autores tem formação na área de Antropologia.

$\mathrm{Na}$ apresentação do livro, as organizadoras explicitam a busca por compreender as políticas públicas em saúde a partir do ponto de vista de "baixo", isto é, de quem vivencia as práticas do Estado. Sendo assim, a obra problematiza as relações de poder existentes, a produção de verdade e as estratégias de sujeitos e de coletividades, a fim de analisar os diversos agenciamentos de processos de saúde-adoecimento. Ainda nesse início, é feita uma breve apresentação dos textos.

$\mathrm{O}$ artigo de Maluf abre esta publicação com uma discussão sobre a biolegitimidade no âmbito das políticas de saúde mental do Brasil, como um dispositivo de produção de direitos por parte dos sujeitos mais vulneráveis. Assim, até mesmo a demanda pelo reconhecimento de uma patologia por parte do Estado torna-se uma luta na proposta de políticas sociais. Como nem sempre a questão de direitos é considerada como legítima, os movimentos e os grupos de pressão apelam para a defesa da vida. A autora evidencia, ainda, que, no contexto do neoliberalismo, as ambivalências do Estado nas políticas de saúde mental tornam-se visíveis em meio às experiências dos sujeitos sociais, o que permite definir o processo estatal como heterogêneo, desigual e até contraditório. Nesse quesito, uma nova medicalização da saúde mental, a racionalização da biomedicina, que afeta 
as políticas sociais, e as formas de abordagens do ciclo de vida das mulheres apontam os limites das próprias políticas. Sendo assim, de forma geral, a autora reforça os desafios para a biolegitimidade de questões sociais importantes, em um contexto que abrange políticas da vida, experiências dos sujeitos sociais e reconhecimento por direitos.

$\mathrm{O}$ artigo seguinte trata sobre gênero, raça e loucura e é de autoria de Quinaglia Silva, Santos e Cruz. As autoras baseiam-se em uma pesquisa quanti-qualitativa, realizada a partir da análise documental de processos e prontuários, no Distrito Federal, tomando como foco mulheres que cumpriram medida de segurança entre os anos de 2013 a 2014. O perfil geral dessas mulheres é composto por negras, solteiras, com baixa escolaridade, desempregadas e que foram presas em razão de crimes cometidos contra o patrimônio. Há uma dupla estigmatização social nelas, por serem consideradas loucas e infratoras. Após desvinculadas dos serviços da justiça, acabam abandonadas pelo Estado, sem receber atendimento nos serviços ambulatoriais de saúde mental, que as deveriam acolher. Ao evidenciar questões de gênero-raça-loucura, as autoras permitem também repensar as políticas públicas direcionadas a essas mulheres, que acabam invisibilizadas pelo processo de estigmatização e de desatenção do Estado.

No terceiro artigo da coletânea, Camargo evidencia a história de Benedita Fernandes, que deu nome a um hospital psiquiátrico localizado no interior de São Paulo, e relaciona sua trajetória de vida às mudanças de compreensão sobre a saúde mental nessas instituições. A arquitetura do prédio também é analisada pela autora, a qual evidencia o isolamento vivenciado pelos pacientes, que eram demarcados pelos muros, pela vigília constante por meio da disposição das enfermarias - e pela separação entre internos. Benedita destacou-se como uma liderança política, social e também espiritual na história da filantropia brasileira, relacionada ao movimento espírita. Após sua morte, os processos de psiquiatrização nos sanatórios ganharam força para o tratamento da loucura.

No artigo seguinte, Fleischer enfoca a atenção dada ao problema de pressão em relação ao grupo de idosos e idosas em um posto de saúde. Os pacientes compreendiam que a assistência recebida seria mais uma "ajuda" profissional do que um direito ofertado pelo estabelecimento de saúde. Os profissionais, por sua vez, estabeleciam uma classificação dos pacientes entre aqueles com pressão "destrambelhada" e aqueles com pressão controlada, ofertando atenção diferenciada a cada um desses perfis. Apesar dessa atenção diferenciada, nos casos em que a pressão subia, somente o paciente era culpabilizado.

No artigo de Costa e Porto, são analisadas as representações dos profissionais de saúde sobre as práticas de aborto legal, mais especificamente observando os "usos" e os "desusos" da objeção de consciência. No âmbito do Rio Grande do Norte, a etnografia feita por essas pesquisadoras acompanhou o Programa de Assistência às Vítimas de Abuso Sexual (PAVAS) para discutir a questão da violência sexual, o estigma do estupro e a demora de atendimento às mulheres vítimas de violência. O programa, no entanto, era pouco divulgado, até mesmo pelos profissionais da rede de atenção. Ao mesmo tempo, a infraestrutura da maternidade pesquisada sofria superlotação, 
pela escassez de serviços na região. As autoras destacam, ainda, que a burocracia pela qual passa a mulher violentada se configura como violência institucional, devido às diversas avaliações profissionais a que são submetidas e às estruturas públicas, que não se conectam para prestar essa atenção. Informam também que, quando o aborto legal é encaminhado, os profissionais que acionam a objeção de consciência parecem ter dificuldade e repulsa de lidar com o fruto da violência.

Em seguida, no livro organizado por Maluf e Quinaglia Silva, o processo de reparação estatal aos ex-internos de colônias hospitalares para hanseníase é estudado por Maricato, à luz de uma legislação que entrou em vigor no Brasil a partir de 2007. A autora acompanhou o trabalho da equipe responsável pelo recebimento e pela análise dos pedidos de reparação para a Comissão Interministerial de Avaliação (CIA), da Secretaria de Direitos Humanos da Presidência da República, em Brasília. Primeiramente, Maricato apresenta a constituição da Comissão, explicando o seu funcionamento, e apresenta o perfil dos relatores envolvidos. Em um segundo momento, ela traz a trajetória de vida de dois sujeitos que demandaram reparação por terem uma vida em segregação, ainda que não tenham permanecido por longo tempo em leprosários. Assim, a autora mostra que, ao analisar a ação de reparação, é preciso considerar a ação autoritária do Estado durante essa demanda, mas também compreender como o Estado esteve ausente no processo de atenção aos portadores de hanseníase. Com isso, são apresentados os efeitos da performatização do
Estado, mostrando ações que diferem do que está prescrito na lei.

Nessa primeira parte da obra, as análises são dedicadas a pensar as práticas do Estado e suas consequências para as populações-alvo. Entretanto, como evidencia Gupta (2012), a moderna burocracia produz sistematicamente arbitrariedades, que geram resultados divergentes para parte da população, sendo relevantes a análise e a discussão destes. Já na segunda parte da coletânea, são evidenciadas as demandas sociais de atenção em saúde e as mobilizações dos atores em questão, para alcançar seus direitos no âmbito do Sistema Único de Saúde (SUS).

$\mathrm{O}$ artigo de Nóbrega analisa os estudos feitos na área da Genética para tornar acessíveis tecnologias que permitem atender pessoas com síndromes raras no Brasil. Nesse caso, a síndrome é de Berardinelli, mais conhecida como doença dos magros. A fim de legitimar ações de cuidado, qualidade de vida e aceitação para crianças com essa síndrome, suas mães se mobilizaram politicamente não apenas para o reconhecimento médico dessa doença, mas também para o reconhecimento moral e simbólico por parte da sociedade. Essa situação estimulou novas pesquisas científicas sobre esta doença rara, buscando uma "cidadania terapêutica", a partir das demandas das mães de crianças afetadas. A rede de relações estabelecida envolveu a comunidade científica na busca de um reconhecimento biossocial, além daquele estabelecido pela administração central, que buscava repensar a condição genética dessa síndrome, para permitir o engendramento de uma bioidentidade ancorada nas novas tecnologias biomédicas.

Para compreender o cuidado como polissêmico, dinâmico e relacional, Longhi estudou o cotidiano 
de um posto de saúde em Pernambuco, até chegar nas relações de parentesco entre usuários do serviço. Desse modo, a rede de relações e a dinâmica do local onde se encontram os usuários tornam a sala de espera para vacinação um ambiente familiar. A pesquisadora ainda evidenciou que as noções de autonomia e de liberdade podem ser ressignificadas no processo de envelhecimento, pois passam por aspectos físicos do próprio indivíduo, mas também por dimensões sócio-históricas, econômicas e políticas que envolvem o ambiente social.

$\mathrm{O}$ artigo de Melo, por sua vez, discute os regimes de verdade sobre a doença "dependência química" a partir de um grupo de ajuda mútua e de uma comunidade terapêutica. A doença, que não está vinculada a uma classe social, parece atingir a pessoa inteira e desmoraliza quem ela é. Assim, para esses sujeitos, somente a abstinência poderia conceder a "sobriedade" para uma identidade positiva. No âmbito da comunidade terapêutica, a terapia laboral visa instrumentalizar o sujeito para o mercado de trabalho, sendo que a disciplina estabelecida pelas regras institucionais busca a reinserção social, após o cumprimento do prazo de tratamento na instituição. Nesse sentido, o que é entendido como recuperação do adicto acaba por naturalizar classificações sociais, calcadas na ideia de autocontrole de emoções e de ações, visto que, durante o tratamento, busca-se constituir cidadãos disciplinados em um mundo de desigualdades.

Saretta discute a subjetividade e a alteridade, a partir de situações vivenciadas por pacientes no contexto do funcionamento de um hospital psiquiátrico, após a Reforma Psiquiátrica. Ao mesmo tempo, o autor mostra seu desconforto com o embate político entre atores que buscavam modificar as propostas desses serviços e outros que entendiam que essas propostas poderiam levar ao fechamento da instituição. Diante de um ato político, o antropólogo aponta o que está sendo evidenciado e o que está sendo deixado de lado nas perspectivas de alguns pacientes e profissionais, de modo que certas vivências e contradições percebidas pelos pacientes não são levadas em consideração na discussão. Com isso, busca apresentar modos de existência divergentes, para refletir sobre o que pensa o paciente a respeito do seu modo de vida e do cuidado institucional.

Dando continuidade a este bloco da coletânea, a partir de um trabalho de campo no âmbito de um Centro de Atenção Psicossocial (CAPS), Andrade analisa a produção de subjetividade dos usuários dos serviços na relação entre categoria de loucura e de doença mental no processo de desinstitucionalização. Assim, evidencia o reconhecimento da diferença entre o que é próprio da doença e o que seria loucura, em uma relação entre razão e desrazão, que leva em consideração a experiência do doente e a singularidade na vivência da doença. Desse modo, no artigo, há uma desnaturalização da doença como categoria universal, onde a autora reflete sobre os modos de nos relacionarmos com a loucura, o que nos permite pensar em estratégias de luta e de resistência aos saberes instituídos.

Cordeiro e Montardo apresentam a etnografia das práticas não biomédicas de cura entre mulheres na zona urbana do Amazonas. Em meio às práticas biomédicas, são etnografados procedimentos tradicionais, referendados nas terras ameríndias para os cuidados no pré e pós-parto, como massagens, que buscam ajudar na formação da criança, e banhos, tanto na mãe 
como no recém-nascido, que visam "limpar" e "proteger" seus corpos. Esse rito de passagem é negado, quando os profissionais de saúde questionam as mães, pois essas práticas se chocam com as recomendações dadas por eles. Dessa forma, as autoras mostram como a cosmologia indígena persiste no espaço urbano.

Diante dessas análises pertinentes à área de saúde pública, podemos destacar que o cuidado nas políticas públicas também está em discussão. Assim, como nos diz Bellacasa (2010), o cuidado é uma tecnologia viva, que demanda um compromisso ético, mas também político, e tem implicações vitais para humanos e não humanos. Dessa forma, pensar o cuidado nas políticas em saúde, na imbricação entre Estado, políticas e agenciamentos, nos permite visualizar os processos, compreender contradições e reorganizar as demandas no âmbito do Sistema Único de Saúde.

\section{REFERÊNCIAS}

Bellacasa, M. P. 2010. Matters of care in technoscience: assembling neglected things. Social Studies of Science 41(1): 85-106. DOI: https://doi. org/10.1177/0306312710380301.

Gupta, A. 2012. Red tape: bureaucracy, structural violence, and poverty in India. Durham: Duke University Press. 